\title{
THE VIEWS OF HR PRACTITIONERS ON ETHICAL ISSUES WITHIN organisations: A South African Perspective
}

\author{
BJ Erasmus \\ School of Management Sciences, University of South Africa \\ Russell Wordsworth \\ Department of Business Management, University of South Africa
}

\begin{abstract}
This article reports on the results of a survey conducted among human resource practitioners in South Africa regarding their involvement in and experience of business ethics and unethical behaviour in their organisations. The results of the study concur with the theoretical perception that human resource managers have an important role to play in the institutionalisation of good ethical behaviour in the organisation, with the majority of respondents reporting that the human resource department is a primary resource for ethical initiatives and that human resource professionals are involved in the formulation of ethics policies. The article provides some insights in terms of the role of the human resource managers in the management of ethics. In so doing, an attempt is made to address the question of whether human resource managers should be the drivers of ethics initiatives in the organisation.
\end{abstract}

JEL L20, M12

\section{1 Introduction}

Business ethics, and more pertinently the management thereof, has in recent years emerged as one of the leading challenges facing modern managers. Whether this increased attention is a result of proactive attempts by managers and academics to come to grips with the complexities of managing in an ethical manner or as a result of the reactive "hype" surrounding corporate scandals such as those faced by Enron, WorldCom and Parmalat, remains debatable. Debate is generally followed by academic inquiry and, as such, business ethics as a field of research has also enjoyed increasing attention in management literature (Martin \& Woldring, 2001: 243). Wells and Schminke (2001: 137) report that between 1990 and 1999, over 4500 books and journal articles explored business ethics issues.

One such debate currently noticeable in management literature deals with the role of the human resource (HR) function and human resource manager in managing business ethics. Martin and Woldring (2001: 244) highlight the ongoing debate on the role of HR management in terms of "carrying the mantle" of ethical stewardship. Brewster, Carey, Dowling, Grobler and Warnich (2003: 28) also highlight the role that the HR function could play in terms of ethical stewardship, and suggest that HR has a role to fulfil in the formulation, communication, monitoring and enforcement of an organisation's ethics programme.

2

\section{Business ethics}

A search for the meaning of the concept of business ethics understandably has its origins with the concept of ethics. According to Shaw (1991: 8), the etymology of ethics suggests its basic concerns to be firstly individual character, including what it means to be "a good person"; and secondly, the social rules 
that govern and limit one's conduct, especially the rules concerning right and wrong, which are often referred to as morality. Buckley, Beu, Frink, Howard, Berkson, Mobbs and Ferris (2001: 13) describe ethics as a traditional area of philosophical inquiry that delves into the normative rules of behaviour. In other words, ethics is about how people ought to behave and thus focuses on duty and the boundaries between right and wrong. In furtherance of this idea, Pratley (1995: 9) ascribes a twofold objective to ethics, namely that it firstly evaluates human practices by calling upon moral standards, and secondly, it may also give prescriptive advice on how to act morally in a specific situation.

Moving from ethics to business ethics, Shaw (1991: 8) defines business ethics as the study of what constitutes right and wrong, or good and bad, in human conduct in a business context. According to Beu and Buckley (2001: 58), one could also add to this a focus on shared value systems that serve to guide, channel, shape and direct the behaviour of individuals in organisations in a productive direction.

While it should be clear that both ethics and business ethics deal with what is right and wrong, it must be borne in mind that both these fields of philosophical inquiry take place within the constraints of subjectivism and relativism. Subjectivism implies that because moral judgements are feelings and not facts, each individual is entitled to his or own ethical standards. Relativism posits that no single ethical theory or approach is universal either because of specific historical or cultural factors or because people's reasons for differing ethical beliefs are equally valid.

\section{3}

\section{The institutionalisation of good business ethics}

Whether organisations should conduct their business in an ethical and responsible manner in which the interests of the organisation (primarily profitability) as well as the individual employee and society are taken into account, is no longer debatable. Schumann (2001:94) notes management guru, Peter Drucker's argument that "what is most important for management to realise is that it must consider the impact of every business policy and action upon society. It has to consider whether the action is likely to promote the public good, to advance the basic beliefs of society and contribute to its stability, strength and harmony". As far back as in 1975, Porter argued that the wellbeing and effectiveness of the organisation as a whole depend on both the technical and moral excellence of its employees (Seutloadi, 1998: 50). Frederickson and Walling (1999: 502) take this viewpoint one step further when they describe ethics and values as a leadership imperative and an ubiquitous consideration in modern management.

With the moral environment of the modern organisation consisting of a complex web of interactions, it is becoming increasingly important for the top management of an organisation to disseminate a clear set of values and morals to their employees. Buckley et al. (2001: 16) support this view and suggest that chief executives have a role to play in communicating and encouraging an ethical consciousness of these values in their organisations. They stress that it is imperative that CEOs deliver, believe in and model the message that their organisation is guided by certain morals and values. This implies that the most fundamental objective of any attempt to institutionalise business ethics or an ethical consciousness should be the generation of preferred behaviours throughout the management and employees of the organisation. McNamara (2001: 1) points out that the attainment of such an objective is dependent not only on the generation of lists of ethical values, or codes of ethics, but also the generation of the policies, procedures and training required to translate values and morals into behaviour. It is at this point that the HR function finds itself or should find itself fulfilling a pivotal role in the institutionalisation of good business ethics.

Traditionally, the role of the HR function in many organisations has been to serve as the systematising, policing arm of executive management. In this role, the HR function served executive agendas well, but was frequently viewed as a roadblock by much of the rest of the 
organisation. Martin and Woldring (2001: 245) argue that the HR function's role has expanded to the extent that HR initiatives have a strategic impact on organisations. According to Ulrich (2003: 2), as the role of the HR function evolves, it should address the needs of the changing organisation. Successful organisations are becoming more adaptable, resilient, quick to change direction and customer-centred. Within this environment, Ulrich (2003: 2) describes the role of the HR function as necessary for line managers in being

- a strategic partner;

- an employee sponsor or advocate and

- a change mentor.

As the HR function assumes a more strategic place in the organisation, so too does its role in creating an ethical consciousness and moral business environment. Brewster et al. (2003: 28) point out that this is not surprising, considering that ethical issues are generally people issues. In support of the HR's role in creating an ethical climate, Buckley et al. (2001: 16) point out that ethical climates are perpetuated with effective attraction, selection and retention strategies, and as such, should be considered partners in creating an ethical culture in the organisation.

As organisations move towards an ethical approach to doing business, the HR function, as strategic partner, should do all it can to support top management in such an endeavour. According to Creelman (2002: 2), the HR function can be instrumental in this move for a number of reasons.

- HR is often the first place employees turn to when they notice policy violations. Each action taken determines how employees perceive enforcement. This will affect even the most senior managers in the organisation. A sensible, solid response effectively communicates the message that programmes are taken seriously. It not only reinforces the action of the employee who reported the infraction, but also emphasises the meaning of the policy for others and demonstrates the company's intention to act in future situations.

- Further, by establishing consistency and logic in the enforcement of every policy, HR contributes to an environment of higher-level ethical thinking across the board.

An examination of current management literature suggests a multiplicity of roles for the HR manager in institutionalising good business ethics. Also evident in management literature (Buckley et al, 2001; SHRM/ERC, 1997; Van Zyl, 2002; Kitson \& Campbell, 1996; Martin \& Woldring, 2001; Miller, 2004) are three broad approaches to institutionalising good business ethics, which could be, and in some instances, are the responsibility of the HR function. These approaches are as follows:

- A code of ethics. Rossouw (2002) states that one way in which managers can institutionalise good ethical behaviour is through ethical codes or written standards of ethical conducts. He goes on to define an ethical code as a document or agreement that stipulates morally acceptable behaviour in an organisation, which defines moral standards that need to be respected by all members.

- $\quad$ Ethics training initiatives. Miller (2004: 7) contends that simply writing and distributing a code of ethics is insufficient to reap the benefits that an organisation could gain by rolling out a code in a thoughtful and effective manner. Ethics training initiatives should be based on the contents of the code of ethics and should allow employees to develop a working knowledge of the code. Kavathatsopolous (2001: 20) takes this one step further and states that ethics training initiatives should create what he refers to as "ethical competence" and should prepare individuals to cope with ethical conflicts.

- An ethics office or ombudsman. The provision of an ethics office or ethics ombudsman is seen as an essential mechanism for the confidential and objective facilitation of fair and equitable resolutions to ethical concerns which may arise in the organisation. While this function can form part of the HR function, and often does, it is preferable to have a neutral office to which employees can address concerns or ethical dilemmas. 
The above approaches have been illustrated in management literature as being significant in the process of institutionalising the good business ethics. Based on this, the presence and effectiveness of codes of ethics, ethics training initiatives and an ethics office/ombudsman were investigated in terms of sample organisations in this study. Findings in this regard are reported in later sections of this article. While it is not prescribed in current literature that the HR function be wholly responsible for the development and dissemination of a code of ethics, the delivery of ethics training and the provision of a neutral ethics office, it would appear that in many instances the HR function does fulfil this role. Van Zyl (2002: 21) points out that the HR function is usually responsible for the distribution of the code of ethics and also for the accompanying training initiatives. In the 1997 SHRM/ERC study conducted in the USA, nearly 70 per cent of respondents reported that the HR department was the primary resource for ethics policies in their organisations. Similar findings were obtained in the current study and are reported on in later sections of this article.

A final role that the HR function can play in terms of institutionalising good business ethics is identified by Buckley et al. (2001: 16) as accountability mechanisms. These authors posit that good ethics become operationalised in the formal and normative accountabilities that occur in organisations. Implicit in this thinking is the notion that people generally expect to be held accountable for their actions and therefore try to identify sources of accountability and tailor their behaviour to accommodate the said accountabilities. This in turn forms the foundation of ethical behaviours. To this end organisations have enacted accountability mechanisms designed to result in adherence to ethical expectations. It is in this regard that the HR function has a key role to play because the said mechanisms include such things as disciplinary systems, performance evaluations, merit compensation, reward systems and employee handbooks, all of which fall within the responsibilities of the HR function.

The above discussion does not, however, imply that overall accountability for the ethical conduct of the organisation should rest with the HR function. This accountability should rest with the CEO and top management, the very place from which ethics and morals should originate, as highlighted at the start of this discussion. The above discussion suggests that the HR function's role as a strategic partner is exactly that. It should assist top management, where possible, to institutionalise an ethical culture based on the ethics and values portrayed and disseminated by top management.

\section{4}

\section{Background to the research problem}

From the above discussion and also from an examination of current management literature (O'Higgins \& Kelleher, 2005; Harris, 2002: 55; Vickers, 2005: 29; Buss, 2004: 127; Driscoll \& Hoffman, 1998: 121; Lachnit, 2002: 10), it would appear that there is little consensus regarding the exact role that HR can play in the institutionalisation of good business ethics. It would also seem that, more importantly, the role the HR function is currently playing in South African organisations in this regard is not well researched, with limited literature available in the South African context. Thus the researcher is guided by the following questions:

- What types of general and HR-related unethical behaviours are observed in South African organisations?

- Do codes of ethics exist in South African organisations?

- What role can the HR function play in institutionalising good business ethics?

- What role is the HR function currently playing in terms of the institutionalisation of good business ethics? 
5

\section{Objectives of the study}

Based on the above background to the research problem, the objective of this paper is to report on the views of HR practitioners on the

- type of unethical behaviour observed by respondents; and the

- role the HR function can and is playing in institutionalising good business ethics in South African organisations.

\section{6}

\section{Research methodology}

\subsection{Target population}

The target population consisted of 2800 registered members of the South African Board for Personnel Practice (SABPP). The aim of the SABPP is to establish, direct and sustain a high level of professionalism and ethical conduct in personnel practice by enabling human resource practitioners to make significant contributions to their profession.

Questionnaires were mailed to all registered members of the SABPP, of which 306 were returned and were included in the study. This provided a response rate of 10.93 per cent.

\subsection{Research instrument}

A questionnaire was designed as a survey instrument. The design of the questionnaire was based on a questionnaire used for a similar study conducted by the Society for Human Resource Management (SHRM) in the USA. Permission was obtained from the SHRM to modify and then administer the questionnaire in the South African context. The following points were covered in the questionnaire:

- A general profile of the home language, qualifications and position of respondents, as well as an indication of the type and size of the organisations for which they work.

- The ethical environment of the organisation, dealing with ethical standards, ethics training and management's approach and commitment to ethics in the organisation.

- Unethical behaviours observed in the organisation.

Although some areas of the research instrument needed to be adapted to reflect the South African context more accurately, the content of the research instrument remained largely the same as the original questionnaire.

\subsection{Statistical procedures}

Descriptive statistics such as the mean, standard deviations and frequency distribution were calculated using the Statistical Analysis System V8.2 (SAS) computer program. Further analysis consisted mainly of t-tests for significance with the level of significance used being 95 per cent as well as chi-squared tests which were conducted on certain items to establish whether significant relationships existed between variables.

7

\section{Results and discussion}

\subsection{Biographical data}

Respondents were from a wide variety of industry sectors with a large proportion from the manufacturing (18.09 per cent); electricity, gas and water (16.12 per cent) and finance and business services (14.47 per cent) industry sectors. A large number (27.96 per cent) of respondents also indicated their type of organisation as "other". Many of the respondents who were grouped under the category "other" were from higher education institutions and consulting firms.

In addition, the majority of respondents (30.46 per cent) were from organisations employing between 1001 to 5000 employees, while a further 25.83 per cent were employed in organisations with more than 5000 people.

Respondents were requested to indicate their position in their organisation. This information is contained in Table 1 below. 
Table 1

Position of respondents in organisations

\begin{tabular}{|l|c|c|}
\hline Position & (N) & (\%) \\
\hline Human resource (HR) director & 35 & 31.67 \\
\hline Assistant HR director & 9 & 30.00 \\
\hline HR manager & 91 & 3.00 \\
\hline Assistant HR manager & 9 & 14.33 \\
\hline HR specialist & 43 & 13.33 \\
\hline HR generalist & 40 & 2.00 \\
\hline HR supervisor & 6 & 22.33 \\
\hline Other & 67 & $\mathbf{1 0 0} \%$ \\
\hline Total & $\mathbf{3 0 0}$ & \\
\hline
\end{tabular}

* 6 missing frequencies (did not indicate job title)

The majority of respondents (30.33 per cent) were human resource managers, followed by a group who were HR specialists (14.33 per cent) and HR generalists (13.33 per cent). The "other" group comprised an array of titles such as payroll specialists, industrial relations specialists, training consultants, administrative managers and employee assistance specialists. In addition to their organisational position, respondents were requested to indicate their academic qualifications. In this regard it can be reported that the majority of respondents (28.81 per cent) were in possession of an honours degree and those with a master's or doctor's degree represented 26.49 per cent. Only a limited number of respondents (18 per cent) were in possession of a national diploma or lower qualification.

\subsection{Unethical behaviour observed}

The results of the study showed a high incidence of observed unethical behaviour, with just over 70 per cent ( 70.26 per cent) of the respondents reporting that they had personally observed some form of unethical behaviour in the year preceding the study.

The questionnaire used in the study identified 23 possible unethical behaviours. Respondents were requested to indicate which of the 23 unethical behaviours they had observed in the 12 months preceding the study. Used as an indicator of the general level of observed unethical behaviour in organisations, a mean of 6.32 observed unethical behaviours (out of a possible 23) was recorded across all respondents. This implies that on average respondents indicated having observed any six of the 23 identified unethical behaviours. The mean also provides a broad indication of the level of unethical behaviour in organisations, and is used at a later stage in this discussion to measure the effectiveness of mechanisms such as ethical codes and ethical training initiatives.

Table 2 indicates the five most frequently observed unethical behaviours in terms of the percentage of respondents who reported observing the said unethical behaviour.

Table 2

Most prominent types of observed unethical behaviour

\begin{tabular}{|c|l|c|}
\hline RANK & \multicolumn{1}{|c|}{ Unethical behaviour } & $\begin{array}{c}\text { Percentage of } \\
\text { respondents }\end{array}$ \\
\hline 1 & Stealing/theft & 62 \\
\hline 2 & Lying to supervisors & 60 \\
\hline 3 & $\begin{array}{l}\text { Misusing the organisation's } \\
\text { assets }\end{array}$ & 53 \\
\hline 4 & Conflicts of interest & 50 \\
\hline 5 & Abusing drugs or alcohol & 46 \\
\hline
\end{tabular}


Other unethical behaviours observed that warrant mention include employees engaging in fraudulent actions, violations of the Basic Conditions of Employment Act and the Occupational Health and Safety Act, as well as lying in reports (Erasmus \& Wordsworth, 2004).

It is significant that of the respondents who stated that they had observed unethical behaviour, only 67 per cent actually reported the incident to a superior. The reasons advanced by respondents for not reporting unethical behaviour included the belief that corrective action would not be taken; the respondent did not trust the organisation to keep the report confidential; a fear of retribution; as well a fear of being branded as someone who is not a team player.

\subsection{Presence and effectiveness of ethical codes, ethics training initiatives and an ethics office/ombudsman}

Respondents were requested to indicate whether or not their organisations had in place any of the three mechanisms identified in the literature, to institutionalise good business ethics. Table 3 below contains the findings in this regard.

Table 3

Presence of a code of ethics, ethics training and an ethics office

\begin{tabular}{|l|c|c|c|}
\hline Response & Code of ethics & Ethics training & $\begin{array}{c}\text { Ethics office/ } \\
\text { ombudsman }\end{array}$ \\
\hline YES & $78 \%$ & $54 \%$ & $45 \%$ \\
\hline NO & $22 \%$ & $46 \%$ & $55 \%$ \\
\hline
\end{tabular}

As indicated in Table 3, a high percentage, more than three quarters, of organisations had a code of ethics in place. However, this declines to just over half in terms of ethics training and decreases even further to under half in terms of an ethics office/ombudsman. It would appear from these statistics that initiatives around the formulation of a set of standards, values and morals have been quite successful, but they have not been followed by substantial efforts to roll out the codes. Buckley et al. (2001: 25) provide a possible explanation for this in what they term "substantive versus symbolic ethics", whereby one must ask whether ethical initiatives are truly substantive or merely symbolic window dressing. In this instance, the creation of a code of ethics, but with little focus on implementation in terms of training and an ethics office, might be seen as somewhat symbolic. Kreitner \& Kinicki (2002) elaborate further on this by referring to ethical laziness, whereby a CEO or manager has good ethical and moral intentions, but fails to create a culture around these intentions. The existence of a code of ethics could also reflect an HRM ethical framework of "human and employment rights", but that not much is done thereafter to support the HRM framework of "ethics of efficiency".

The study also sought to determine the efficacy of the above three mechanisms in addressing unethical behaviour. This was done using the mean score for unethical behaviours observed (see sec 7.2) and testing for significant relationships between the mean score and the presence of codes of ethics, ethics training initiatives and an ethics office/ombudsman. This was achieved using the t-test for significance. All three mechanisms were illustrated to positively influence the level of observed unethical behaviour in sample organisations (note that positive influence implies that in organisations where, for example, a code of ethics existed, the mean score of unethical behaviours was less than in organisations that did not have a code of ethics). A highly significant difference was found to exist in terms of the level of unethical behaviour observed in organisations with a code of ethics and those without a code of ethics. This relationship is presented in Tables 4 and 5. 
Table 4

Relationship between written ethical standards and unethical behaviour using the mean score

\begin{tabular}{|l|r|r|r|c|}
\hline $\begin{array}{l}\text { Presence of written ethical } \\
\text { standards }\end{array}$ & (N) & $\mathbf{X}$ & $\mathbf{S}$ & T \\
\hline Yes & 167 & 6.773 & 4.065 & $-3.04^{* *}$ \\
\hline No & 42 & 8.929 & 4.256 & \\
\hline Total & 209 & & & \\
\hline
\end{tabular}

${ }^{* *} \mathrm{p}<0.01$

Table 5

T-test procedure on the relationship between written ethical standards and unethical behaviour

\begin{tabular}{|l|c|c|c|c|}
\hline Variable & Method & Variances & T-value & Alpha \\
\hline MI & Pooled & Equal & -3.04 & $0.0026^{*}$ \\
\hline
\end{tabular}

While the findings illustrated that the presence of ethics training and an ethics office/ombudsman were shown to positively influence the level of unethical behaviour, the t-test procedure did not reveal significant relationships at the 95 per cent level of significance. Hence these tables are not reported in the paper.

The above findings illustrate what is reported in theory, namely that the presence of a code of ethics, ethics training and an ethics ombudsman all assist in the process of institutionalising good business ethics.

Further statistical analysis was performed on the data to determine whether biographical factors such as the size of the organisation and type of industry sector had a significant influence on the level of observed unethical behaviour. In terms of the industry size, no significant differences were shown to exist in terms of the level of observed unethical behaviour and the size of the organisation. Through a multiple pairwise comparison, however, differences in the level of unethical behaviour were shown to exist among different industry sectors. A significant difference was found to exist in terms of the F-test (see Table 6). Multiple pairwise ttests were performed to determine which type of organisations contributed to this significant difference $(\mathrm{F}=1.95$, df $=11.195, \mathrm{p}<0.05)$.

Table 6

F-test for type of organisation and level of unethical behaviour

\begin{tabular}{|l|c|c|c|c|}
\hline Source & DF & Sum of squares & Mean square & F-value \\
\hline Model & 11 & 359.61 & 32.69 & $1.95^{*}$ \\
\hline Error & 195 & 3261.79 & 16.73 & \\
\hline Corrected total & 206 & 3621.40 & & \\
\hline
\end{tabular}

${ }^{*}: p<0.05$

The analysis showed that significant differences existed between community, social and personal services organisations $(X=12.286)$ and electricity, gas and water $(X=6.610)$; finance and business services $(X=6.565)$; construction $(X=6)$; manufacturing $(X=5.892)$ and catering, accommodation and other trade organisations $(X=5)$. It is somewhat perplexing to note that the community, social and personal services sector had the highest average number of unethical behaviours observed. Although these institutions are put in place to serve the 
public and are often non-profit organisations, they have a significantly higher level of observed unethical behaviour. The reasons for this difference could not be determined in this study but could be considered as a further research possibility.

\subsection{HR's role in institutionalising good business ethics}

The findings of the study suggest that the HR function plays a vital role in creating an ethical environment in the organisation. In the majority of cases respondents in the study reported that they are involved in ethics initiatives in the organisation. Respondents were requested to indicate whether they agreed or disagreed with a number of statements that dealt with the role of the HR department in ethics initiatives. This was done using a five-point Likert scale and the findings in this regard are reported in Table 7 below. (Note that 1 on the scale denoted "strongly agree" and 5, "strongly disagree".)

Table 7

Role of the HR function in ethics initiatives

\begin{tabular}{|l|c|c|c|}
\hline Role of HR & N & Mean & $\begin{array}{c}\text { Standard } \\
\text { deviation }\end{array}$ \\
\hline $\begin{array}{l}\text { The HR department is a primary resource for } \\
\text { my organisation's ethics initiative }\end{array}$ & 299 & 2.1806 & 1.3314 \\
\hline $\begin{array}{l}\text { HR professionals are involved in formulating } \\
\text { ethics policies for my organisation }\end{array}$ & 299 & 2.2709 & 1.3248 \\
\hline $\begin{array}{l}\text { HR professionals are not part of the ethics } \\
\text { infrastructure, but are often tasked with } \\
\text { cleaning up the messes caused by ethics } \\
\text { violations }\end{array}$ & 297 & 2.8721 & 1.4854 \\
\hline $\begin{array}{l}\text { The individuals responsible for administering } \\
\text { the ethics programme are qualified for the task }\end{array}$ & 290 & 2.5552 & 1.2445 \\
\hline $\begin{array}{l}\text { Employees at my organisation know where to } \\
\text { address their ethical concerns }\end{array}$ & 293 & 2.6621 & 1.4185 \\
\hline
\end{tabular}

The above findings show that in the majority of organisations, the HR function plays a key role in ethics initiatives and is often directly involved in the development of ethics policies. Based on the above findings and those in the previous section, it would seem that one could conclude that the HR function in many instances would be responsible for, or at least be involved in, the formulation of a code of ethics, ethics training initiatives, and in some instances, act as an ethics office where employees can raise ethical issues. SHRM/ERC (1997:5) report that two key indicators of the usefulness of ethical initiatives are whether employees know where to address ethics concerns and whether the individuals responsible for administering the ethics initiatives are qualified for the task. In this regard, only 53.44 per cent of the respondents stated that they believe employees know where to address their ethical concerns, while 59.04 per cent of the respondents felt that the person responsible for ethics initiatives was qualified to do so.

The above results also suggest that while in many instances the HR function, whether by choice or not, finds itself responsible for ethics initiatives, this role might not be formalised as such in the organisation, with employees not knowing where to address these concerns and the HR function/manager not fully prepared for the role of managing ethics initiatives.

To determine whether perceptions differed at different levels in the HR function regarding HR's role in managing ethics, chi-squared tests were conducted between these two items. No significant differences were found on the 95 per 
cent significance level. Significant differences were also not evident when the results were compared across different organisational sizes, which is surprising considering how the role and importance of the HR function might differ in small to large organisations.

The role that HR managers play in ethics initiatives and how they go about fulfilling this role is influenced by factors both inside and outside the organisation. To this end, the study sought the opinions of respondents with regard to factors that influence the ethical behaviour of HR personnel in the organisation. A fivepoint Likert scale was once again used for this purpose. (Note that 1 on the scale denoted "no influence", while 5 denoted "great influence".) The results in terms of influence on ethical behaviour are presented in Table 8 below and are ranked from most influence to least influence.

Table 8

Factors influencing ethical behaviour of HR personnel

\begin{tabular}{|l|c|c|c|}
\hline Factor of influence & $\mathbf{n}$ & Mean & $\begin{array}{c}\text { Standard } \\
\text { deviation }\end{array}$ \\
\hline Personal values & 208 & 4.0865 & 1.0320 \\
\hline Attitudes/behaviour of senior management & 209 & 3.9904 & 1.1308 \\
\hline Attitudes/behaviour of supervisor & 206 & 3.6553 & 1.1186 \\
\hline Internal drive to succeed & 208 & 3.6154 & 1.0615 \\
\hline Performance pressures & 209 & 3.5981 & 1.0657 \\
\hline No threat of punishment & 204 & 3.2059 & 1.2891 \\
\hline Political pressures & 209 & 3.1675 & 1.3748 \\
\hline Lack of standards within profession & 208 & 3.1490 & 1.3084 \\
\hline Declining resources & 207 & 3.0386 & 1.1940 \\
\hline Friends/co-workers & 204 & 3.0245 & 1.1161 \\
\hline Internal competition & 205 & 2.9220 & 1.1938 \\
\hline Lack of legislation & 205 & 2.6927 & 1.3241 \\
\hline
\end{tabular}

Personal values are highlighted in the above table as having the most influence on the ethical behaviour of HR practitioners, which is understandable when viewed from the perspective of Buckley et al. (2001), who describe business ethics as a shared value system that serves to guide, channel, shape and direct the behaviour of individuals in organisations in a productive direction. Personal values are followed very closely by the attitudes and behaviours displayed by senior management and to a lesser degree supervisors and line managers. This again accentuates the views highlighted earlier that the CEO and top management should be the cornerstone of any attempt to create a climate of ethical consciousness. This view is further emphasised by O'Higgins and Kelleher (2005: 276).

A comparison of the above findings with the hypotheses made by Beu and Buckley (2001: 61) reveals some interesting similarities and disparities. These authors hypothesise that individuals specifically held accountable for results and behaviour will engage in the least unethical behaviour. In this study, respondents report that no threat of punishment has a high influence on one's ethical behaviour which is consistent with the hypothesis made. This hypothesis could also provide some explanation for the high level of observed unethical behaviour, in that many respondents did not report the behaviour because they felt 
nothing would be done about it (people would not be held specifically accountable).

Beu and Buckley (2001: 63) further posit that individuals with a high internal drive to succeed (Type A personalities) are more likely to engage in unethical behaviour. The results of this study also show one's internal drive to succeed as having a high influence on ethical behaviour. One disparity with the current results and the hypotheses made by Beu and Buckley (2001: 63) is in the area of internal competition. Although these authors suggest that individuals who are highly competitive are more likely to engage in unethical behaviour, the results of this study suggest that the respondents perceive an internally competitive environment to have only a minor influence on one's ethical behaviour. Further statistical analysis was conducted in the form of chi-squared tests using the Pearson correlation coefficient to determine whether the factors influencing ethical behaviour differed across organisation size and whether they differed in terms of the position held by respondents. These results are presented in Table 9 below.

\section{Table 9}

Further analysis (chi-squared tests) of the factors influencing the ethical behaviour of HR personnel

\begin{tabular}{|l|c|c|c|}
\hline Factor of influence & $\mathbf{n}$ & Company size & Position held \\
\hline Personal values & 208 & 0.534 & $0.055^{* *}$ \\
\hline Attitudes/behaviour of senior management & 209 & 0.354 & 0.729 \\
\hline Attitudes/behaviour of supervisor & 206 & 0.130 & 0.206 \\
\hline Internal drive to succeed & 208 & $0.084^{* *}$ & 0.712 \\
\hline Performance pressures & 209 & 0.266 & 0.790 \\
\hline No threat of punishment & 204 & 0.064 & 0.638 \\
\hline Political pressures & 209 & 0.841 & 0.945 \\
\hline Lack of standards in profession & 208 & 0.123 & 0.332 \\
\hline Declining resources & 207 & $0.032^{* *}$ & 0.759 \\
\hline Friends/co-workers & 204 & 0.048 & 0.195 \\
\hline Internal competition & 205 & $0.000^{* *}$ & 0.672 \\
\hline Lack of legislation & 205 & 0.413 & 0.566 \\
\hline
\end{tabular}

Statistical tests conducted at the 95 per cent confidence interval

** Denotes the existence of significant differences

The table above illustrates some consistency of responses across groups, both in terms of company size and position of the respondents, with few significant differences evident. Although a lack of standards in the HR profession was reported by respondents as not having a substantial influence on the ethical behaviour of HR personnel, at the same time 90.37 per cent of the respondents stated that the SABPP should prescribe ethical standards for the profession.
A final question posed to respondents on HR's role in institutionalising business ethics dealt with the frameworks that HR practitioners should use to ensure that ethical standards are maintained in the organisation. The results of this are presented in Table 10. 
Table 10

Frameworks to institutionalise ethical behaviour

\begin{tabular}{|l|c|c|}
\hline HRM Framework & $\mathbf{n}$ & Mean \\
\hline $\begin{array}{l}\text { Emphasise openness and consultation on matters affecting HRM } \\
\text { (human and employment rights) }\end{array}$ & 259 & $84 \%$ \\
\hline Legal approach (social and organisational justice) & 45 & $14.7 \%$ \\
\hline $\begin{array}{l}\text { Emphasise the roles and responsibility of the organisation and place } \\
\text { less emphasis on the individual (community of purpose) }\end{array}$ & 57 & $18.6 \%$ \\
\hline $\begin{array}{l}\text { Capitalism as a model for ethical behaviour, that is, relying on the } \\
\text { bottom-line ethics of the marketplace (ethics of efficiency) }\end{array}$ & 18 & $5.9 \%$ \\
\hline $\begin{array}{l}\text { By treating people fairly, truthfully and avoiding injury to others in all } \\
\text { possible ways (Biblical ethical injunction) }\end{array}$ & $223 \%$ \\
\hline Emphasising the keeping of promises to employees and applicants & 138 & $73.1 \%$ \\
\hline
\end{tabular}

Note: Since the respondents could indicate more than one response percentages will not add up to 100

The HRM ethical framework selected by the majority of respondents ( 84 per cent) is the "human and employment rights" approach, followed closely by the "Biblical ethical injunction" approach. Openness and consultancy are emphasised in the case of the "human and employment rights" approach, while truthfulness and fairness are the essence of the "Biblical ethical injunction" approach. Keeping promises to employees is the third approach (45 per cent) chosen by respondents. The approaches selected by the respondents also correspond with aspects of the Bill of Rights in the South African Constitution, further supported by the fact that the majority of South Africans categorise themselves as Christians. Although ethical frameworks are developed to better understand and analyse HRM ethics, a compartmental approach to this issue should be avoided.

\subsection{Areas of HRM that lend themselves to unethical behaviour}

The preceding discussion has shown that the HR manager/function has a role to play in creating an ethical environment and also that the ethical behaviour of the HR practitioner is influenced by an array of factors. Likewise, the HR manager operates in and has an influence on a number of areas within the scope of HRM. Once again, a five-point Likert scale was used to question respondents about which areas of HRM are most likely to lend themselves to unethical behaviour, the findings of which are presented in Table 11 below. (Note that 1 on the scale denoted "not at all" and 5, "greatly").

Table 11

Areas of HRM that lend themselves to unethical actions

\begin{tabular}{|l|l|l|c|}
\hline Aspect of HRM & $\mathbf{n}$ & Mean & $\begin{array}{c}\text { Standard } \\
\text { deviation }\end{array}$ \\
\hline Nepotism & 290 & 2.7345 & 1.3902 \\
\hline Affirmative action & 287 & 2.6934 & 1.4277 \\
\hline Performance appraisals & 287 & 2.6376 & 1.3693 \\
\hline Diversity over merit & 283 & 2.5901 & 1.2778 \\
\hline Rewards & 282 & 2.5887 & 1.3581 \\
\hline Remuneration & 287 & 2.5749 & 1.3433 \\
\hline
\end{tabular}




\begin{tabular}{|l|l|l|c|}
\hline Succession planning & 281 & 2.3950 & 1.2693 \\
\hline The use of part-time labour & 285 & 2.3825 & 1.3496 \\
\hline Recruitment advertising & 284 & 2.3134 & 1.3827 \\
\hline Disclosure of info & 283 & 2.3110 & 1.1678 \\
\hline Empowerment programmes & 281 & 2.2206 & 1.2310 \\
\hline Flexible working patterns & 282 & 2.0284 & 1.1987 \\
\hline Employment contract & 280 & 1.6893 & 1.0973 \\
\hline Psychometric testing & 278 & 1.6259 & 0.9708 \\
\hline
\end{tabular}

The priority areas (see Table 11) that lend themselves most to unethical actions in organisations are nepotism, affirmative action interventions, the execution of performance appraisals, diversity issues over merit and rewards systems. The areas lowest on the list are empowerment programmes, flexible working patterns, the employment contract and psychometric testing.

Further statistical analysis was performed on the data to determine whether biographical factors such as the size of the organisation and the position of respondents in the organisation had a significant difference on the areas that lend themselves to unethical actions. In terms of the position of respondents (see Table 1) no significant differences (chi-squared test procedure on the 95 per cent level of significance) were found to exist, but significant differences were found using the size of the organisation (see Table 12 below).

\section{Table 12}

Further analysis (chi-squared test) of the aspects of HRM that lend themselves to unethical behaviour

\begin{tabular}{|l|l|c|}
\hline Aspect of HRM & N & Company size \\
\hline Recruitment advertising & 280 & 0.569 \\
\hline Nepotism & 286 & 0.020 \\
\hline Affirmative action & 283 & $0.003^{* *}$ \\
\hline Diversity over merit & 279 & 0.046 \\
\hline Psychometric testing & 274 & 0.194 \\
\hline Employment contract & 276 & 0.080 \\
\hline Performance appraisals & 283 & $0.002 * *$ \\
\hline Disclosure of info & 279 & 0.037 \\
\hline Succession planning & 277 & 0.290 \\
\hline Empowerment programmes & 277 & 0.176 \\
\hline Remuneration & 283 & 0.276 \\
\hline Rewards & 278 & 0.010 \\
\hline The use of part-time labour & 281 & 0.455 \\
\hline Flexible working patterns & 278 & 0.246 \\
\hline
\end{tabular}


The results depicted in the above table indicate significant differences in terms of company size on the items of affirmative action and performance appraisals. An analysis of the chisquared tables reveals that both these areas are viewed as lending themselves less to unethical behaviour in smaller organisations (500 or fewer employees). This is possibly explained by the fact that smaller organisations, because of their nature, may have less formalised performance appraisal systems and performance is probably evaluated more frequently on an informal basis because of a lack of human resource sections. Also, in smaller organisations the performance appraisal system is not the main source for promotion and other important human resource-related decisions. Succession planning is probably not even considered as an important dimension to the success of smaller organisations. Larger organisations (more than 1000 but fewer than 5000 employees) may have performance appraisals systems that are not properly managed, which may lead to unethical decisions and impact negatively on succession planning decisions. The importance of a well-designed performance appraisal system in organisations and the smooth execution of the various steps in the process are once again emphasised. Many decisions affecting employees like succession planning and pay, are based on the outcome of performance appraisals of employees and the management of organisations need to be aware of the potential impact this could have on the effectiveness of the organisation.

In terms of the significant differences observed on the item of affirmative action, this is most likely explained by the fact that smaller organisations (fewer than 50 employees) are applying the Employment Equity Act regulations more loosely and are also not under constant scrutiny from the Department of Labour.

\section{8}

\section{Conclusion}

The results of the study showed that a high level of unethical behaviour was observed by respondents in their organisations. These results would suggest a degree of justification in the observed increase in business ethics as a topical subject in management literature.

The preceding literature study showed that the HR function is well poised to play an instrumental role in addressing such high levels of unethical behaviour. The literature study also suggested three key mechanisms to institutionalise good business ethics, namely a code of ethics, ethics training initiatives and an ethics office/ombudsman. The empirical study showed that in all three instances the presence of these mechanisms did reduce the level of observed unethical behaviour. What is of concern, however, is the fact that only a written code of ethics seemed to be implemented extensively in organisations, while ethics training initiatives and an ethics office/ombudsman featured in roughly half of the organisations, implying that effective roll-out, driving and support of ethics initiatives is not taking place at the desired levels. The reason for this could lie in the perceived ambiguity regarding who is responsible for ethics initiatives in the organisation. In this regard there exists, as the SHRM/ERC (1997: 2) reports, some ambiguity around the role of the HR function relative to ethics initiatives, where a large proportion of the respondents report that they are involved in ethics issues and the development of ethics codes, yet are often not part of the formal ethics infrastructure. This is also evident in the South African results with respondents stating that often unethical behaviour was not reported because they did not have confidence that the mechanisms in place would adequately address their concerns.

Hence the final question that needs to be addressed, is: What is the role of the HR function in institutionalising good business? Buckley et al. (2001: 17) answer this question with the following quotation: "what is important is that ethical values are inculcated in employees and ethical behaviour results". It was proposed in the above literature study that the said ethical values should come from the CEO and top management and flow through the organisation, creating an ethical culture and consciousness. In so doing the CEO and top management should remain the champions of good business ethics in the organisation. However, as the HR function 
assumes its role as strategic partner in the organisation, it must facilitate as far as possible the creation of an ethical culture --- and herein lies its role. Since ethical issues are people issues, the HR function should be involved in the development of a code of ethics. More importantly, the HR function should act as an implementation agent, ensuring that the code of ethics is not merely a symbolic document but a substantive tool through which ethics issues can be resolved. To achieve this, however, the role of the HR function needs to be clarified in the organisation to ensure that it is prepared for this facilitation role. As Martin and Woldring (2001: 244) point out, where organisations undertake ethics initiatives, HR is likely to be involved. It is, however, suggested that ethics in an organisation should be the responsibility of each employee and that the overall coordination of this task should lie with an "ethics manager/ombudsman" in the organisation.

\section{9}

\section{References}

1 BEU, D.S. \& BUCKLEY, M.R. (2001) “The hypothesized relationship between accountability and ethical behaviour", Journal of Business Ethics 34: 57-73.

2 BREWSTER, C.; CAREY, L.; DOWLING, P.; GROBLER, P. \& WARNICH, S. (2003) Contemporary Issues in Human Resource Management, Cape Town: Oxford University Press.

3 BUCKLEY, M.R.; BEU, D.S.; FRINK, D.D.; HOWARD, J.L.; BERKSON, H.; MOBBS, T.A. \& FERRIS, G.R. (2001) "Ethical issues in human resource systems", Human Resource Management Review, 11: 11-29.

4 BUSS, D. (2004) "Corporate compasses: The increasingly important corporate ethics function doesn't have to be a challenge to HR's role in upholding ethical business behaviour", $H R$ Magazine, 49(6): 126-131.

5 CREELMAN, D. (2002) "HR: Is it living up to its role in promoting corporate ethics", www.hr.com.

6 DRISCOLL, D. \& HOFFMAN, M.W. (1998) "HR plays a central role in ethics programmes", Workforce, 77(4): 121-124.

7 ERASMUS, B.J. \& WORDSWORTH, R. (2004) "Aspects of business ethics in South Africa", South African Journal of Labour Relations, 28(2): 77-112.
8 FREDERICKSON, H.G. \& WALLING, J.D. (1999) "Ethics in contemporary human resource management”, Public Personnel Management, 28(4): 501-504.

9 HARRIS, L. (2002) "Achieving a balance in human resourcing between employee rights and care for the individual", Business and Professional Ethics Journal, 21(2): 45-58.

10 KAVATHATSOPOLOUS, I. (2001) Ethical Competence Training for Individuals and Organisations, HCI Department, Uppsala University, Uppsala.

11 KITSON, A. \& CAMPBELL, R. (1996) The Ethical Organisation: Ethical Theory and Corporate Behaviour", Macmillan: Hampshire.

12 KREITNER, R. \& KINICKI, A. (2002) Organisational behaviour, McGraw Hill: New York.

13 LACHNIT, C. (2002) "Why ethics is HR's issue", Workforce, 81(3): 10.

14 MARTIN, G. \& WOLDRING, K. (2001) "Ready for the mantle: Australian human resource managers as stewards of ethics", International Journal of Human Resource Management, 12(2): 243-255.

15 MCNAMARA, C. (2001) "Complete guide to ethics management: An ethics toolkit for managers", Unpublished guidebook, www.mapnp. org/library/ethics.htmn.

16 MILLER, W. (2004) "Implementing an organisational code of ethics", International Business Ethics Review 7(1): 6-10.

17 O'HIGGINS, E. \& KELLEHER, B. (2005) "Comparative perspectives on the ethical orientations of human resources, marketing and finance functional managers", Journal of Business Ethics, 56: 275-288.

18 PRATLEY, P. (1995) The Essence of Business Ethics, Hertfordshire: Prentice-Hall.

19 ROSSOUW, G. (2002) Business Ethics in Africa, Oxford: Cape Town.

20 SCHUMANN, P.L. (2001) "A moral principles framework for human resource management ethics", Human Resource Management Review 11: 93-111.

21 SEUTLOADI, J.K. (1998) "Ethical issues in the management of human resources", Journal of Black Theology in South Africa, 12(2): 49-59.

22 SHAW, W.H. (1991) Business Ethics, Wadsworth: Belmont, Calif.

23 SOCIETY FOR HUMAN RESOURCE MANAGEMENT/ETHICS RESOURCE CENTRE (1997) Business Ethics Survey Report, Alexandria. 
24 ULRICH, D. (2003) "The new role of the human resources professional”, About Inc. www.about. com.

25 VAN ZYL, E. (2002) "Role of the human resource management function in the development and implementation of an ethical corporate culture", Acta Criminologica, 15(2): 19-25.

26 VICKERS, M. R. (2005) "Business ethics and the HR role: Past, present and future", Human Resource Planning, 28(1): 26-32.
27 WELLS, D. \& SCHMINKE, M. (2001) "Ethical development and human resources training: An integrative framework", Human Resource Management Review, 11: 135-158.

28 WINSTANLEY, D \& WOODALL, J. (1996) "Business ethics and human resource management”, Personnel Review, 25(6): 5. 